\title{
Penentuan Kurva Kelengkungan Tulang Belakang pada Citra X-ray Skoliosis Menggunakan Metode Fuzzy C-Means
}

\author{
Bagus Adhi Kusuma \\ STMIK Amikom Purwokerto, Indonesia \\ Email: bagus@amikompurwokerto.ac.id
}

\begin{abstract}
Abstrak
Skoliosis merupakan salah satu penyakit yang memerlukan deteksi X-ray. Deteksi dini sangat diperlukan oleh pasien pengidap skoliosis. Berdasarkan informasi yang didapat lewat deteksi dini, akan memungkinkan dokter untuk mengambil langkah awal pengobatan secara cepat. Penentuan kurva tulang belakang merupakan langkah awal yang berfungsi untuk mengukur seberapa parah sudut kurva skoliosis. Tingkat keparahan sudut kurva pada penyakit skoliosis ini dapat dihitung dengan menggunakan Sudut Cobb. Maka dari itu, dengan membuat perkiraan kurva tulang belakang, kita juga dapat mengestimasi Sudut Cobb tersebut. Berdasarkan metode dari penelitian sebelumnya, nilai pengukuan interobserver dapat menyentuh $11.8 \mathrm{o}$ dengan kekeliruan pengukuran intraobserver sebesar 6o. Dengan demikian, selama proses perhitungan Sudut Cobb, aspek subjektif merupakan hal yang lumrah dan masih dapat ditolerir hingga saat ini. Namun aspek ini juga dapat menjadi masalah yang paling sering muncul ketika menggunakan metode pengukuran manual oleh dokter. Penelitian ini mengusulkan algoritma untuk mengukur kurva tulang belakang dengan bantuan komputer dalam bentuk citra X-ray secara cepat dengan tingkat kesalahan yang masih dalam batas toleransi. Proses pra-pemrosesan data dilakukan dengan menggunakan deteksi tepi Canny. Algoritma pengelompokan Fuzzy C-Means (FCM) dapat mendeteksi titik pusat dari ruas tulang belakang setelah segmentasi prapemrosesan deteksi tepi. Pembentukan kurva tulang belakang dilakukan dengan metode polynomial curve fitting dengan hasil akurasi 2.45o. Berdasarkan informasi kurva tulang belakang, tingkat keparahan dari bentuk kurva skoliosis dapat diklasifikasikan ke dalam empat jenis, normal, ringan, sedang dan parah. Dari empat tingkatan tersebut, maka dapat sistem ini dapat digunakan untuk mendeteksi apakah seseorang terkena kelainan skoliosis atau tidak.
\end{abstract}

Kata kunci: skoliosis, sudut cobb, kurva polinomial, deteksi tepi Canny

\section{Abstract}

Scoliosis is a disorder that requires X-ray detection. Early detection is needed by patients with scoliosis. Based on information obtained through early detection, it will enable doctors to take the initial steps of treatment quickly. Determination of the spinal curve is the first step that serves to measure how severe the angle of the scoliosis curve. The angular severity of the scoliosis disorder can be calculated using the Cobb angle. Therefore, by estimating the spinal curve, we can also estimate the Cobb's angle. Based on the method from the previous study, the interobserver value can touch $11.8 \mathrm{o}$ with an error in the intraobserver measurement of 6o. Thus, during the Cobb Angle calculation process, subjective aspects are common and can still be tolerated today. But this aspect can also be the most frequent problem when using manual measurement methods by doctors. This study proposes an algorithm to measure the curve of the spine with computer-aided of X-ray images quickly with a error level error that is still within tolerance value. The data pre-processing process is carried out using Canny edge detection. The Fuzzy CMeans clustering algorithm (FCM) can detect the center point of the vertebral segment after segmentation of edge detection pre-processing. Formation of the spinal curve is done by the polynomial curve fitting method with the results of accuracy of 2.45o. Based on information on the spinal curve, the severity of the form of the scoliosis curve can be classified into four types, normal, mild, moderate and severe. Of the four levels, this system can be used to detect whether a person has scoliosis or not.

Keywords: scoliosis, cobb angle, polynomial curve, Canny edge detection

\section{PENDAHULUAN}

Skoliosis merupakan kelainan tiga dimensi dari tulang belakang yang biasanya ditemukan pada $2 \%$ - $4 \%$ populasi remaja, dan $70 \%$ - $80 \%$ penyebab skoliosis masih belum diketahui secara pasti [1]. Berdasarkan bentuk kurvanya, skoliosis dapat dikelompokkan ke dalam dua jenis, yaitu tipe $\mathrm{C}$ dan tipe $\mathrm{S}$ [2]. Saat ini, untuk deteksi dini skoliosis dapat menggunakan beberapa metode seperti Adam's bend test [3], skoliometrik [4], moire topography [5], raster stereography [6] dan laser [7], akan tetapi semua cara tersebut belum menjamin akurasi dari tingkat keparahan skoliosis.

Untuk menentukan tingkat keparahan kelainan ini biasanya dilakukan oleh dokter dengan menghitung sudut kurva tulang belakang ketika membaca citra X-ray. Sudut Cobb merupakan metode yang umum digunakan untuk meninjau kurva skoliosis dalam radiograf frontal [8]. Ketika akan menentukan sudut Cobb, langkah pertama yang harus dilakukan adalah mengidentifikasi dan menentukan endplate. Endplate merupakan ruas dengan kemiringan terekstrim dari sisi atas (superior) dan bawah (inferior) ruas tulang belakang. Kemudian diambil garis tegak lurus sepanjang superior dan inferior untuk ditetapkan sebagai Sudut Cobb.

Sudut Cobb dengan nilai dibawah $10^{\circ}$ belum termasuk kategori skoliosis. Berdasarkan derajat kelengkungannya, tingkat keparahan skoliosis dapat diklasifikasikan ke dalam empat jenis, normal, ringan, sedang dan parah. Skoliosis dikategorikan ringan jika sudut Cobb berkisar $10^{\circ}$ hingga $25^{\circ}$. Dalam kategori ringan, kurva Cobb akan diawasi secara rutin sampai pertumbuhan kurva tidak bertambah secara signifikan. Skoliosis sedang dengan sudut kurva $25^{\circ}$ hingga $45^{\circ}$ sangat disaranakan untuk memakai penyangga tulang belakang. Jika anda menderita skoliosis parah dengan sudut Cobb lebih dari $45^{\circ}$, maka dokter akan merekomendasikan operasi [9]. 
Secara umum, perubahan $5^{\circ}$ atau lebih dalam dua kali periode pengawasan X-ray dapat menandakan peningkatan kurva [10].

Pengukuran sudut Cobb antara satu dokter dengan lainnya dapat bervariasi. Tingkat kesalahan pengukuran interobserver dapat mencapai $11.8^{\circ}$ dengan penyimpangan standar $3.3^{\circ}$. Tingkat kekeliruan pengukuran intraobserver tertinggi seharusnya tidak lebih dari $6^{\circ}$ dengan standar penyimpangan $2^{\circ}[2]$.

Citra X-ray skoliosis tidak hanya memuat gambar tulang belakang saja. Organ lain disekitar tulang belakang, terutama tulang rusuk juga seringkali muncul. Selain itu, beberapa rumah sakit maupun laboratorium berpotensi menghasilkan kualitas citra X-ray yang rendah yang mana akan berdampak pada kekeliruan pengukuran yang secara umum terjadi baik pada interobserver maupun intraobserver. Beberapa peneliti [8] [11] [12] [13] menentukan ROI (Region of Interest) secara manual untuk menghindari kekeliruan dan meningkatkan akurasi dari suatu sistem.

Penelitian ini mengembangkan pendekatan baru untuk memperkirakan besarnya sudut Cobb lewat konsep persamaan polynomial curve fitting seperti yang dideskripsikan dalam penelitian oleh Sardjono dkk [2] dengan menggunakan metode pra-pengolahan dan inti yang berbeda. Demi menyederhanakan masalah yang muncul dalam penelitian yang telah dilakukan sebelumnya, yaitu derau yang berasal dari area selain tulang belakang (rusuk, abdomen, jantung dll), peneliti berusaha untuk menempatkan seed point untuk menentukan ROI. Algoritme ini dapat diaplikasikan untuk mendeteksi kedua jenis skoliosis (tipe $\mathrm{C}$ dan tipe $\mathrm{S}$ ). Beberapa proses dalam penelitian ini seperti filter median dan deteksi tepi Canny digunakan untuk menentukan ROI. Beberapa peneliti membandingkan deteksi tepi terdapat beberapa metode yang dapat digunakan seperti Sobel, Prewitt, Roberts, dan Canny [14]. Dalam menentukan ROI secara otomatis, performa deteksi tepi Canny dinilai yang terbaik dibandingkan metode lainnya [15]. Fungsi polinomial order 5 digunakan untuk menetapkan perkiraan kurva berdasarkan pada titik secara otomatis. Pada akhirnya, kurva skoliosis pada citra X-ray dapat dihitung dan diklasifikasikan ke dalam 4 kategori, normal, ringan, sedang dan parah.

\section{TEORITIS}

\subsection{Pra-pemrosesan}

Pada penelitian ini, penentuan sudut Cobb dilakukan secara terkomputerisasi. Penelitian ini menggunakan software MATLAB dalam keseluruhan proses komputasinya. Gambar 1 merupakan alur penelitian yang kami usulkan. Pertama-tama, dilakukan proses konversi citra X-ray menjadi citra grayscale. Kedua, tetapkan titik penempatan awal pada semua tipe skoliosis. Langkah ketiga, bagi citra kedalam 12 sub-gambar untuk kalkulasi terpusat pada ROI [16]. Keempat, pemilahan sub-gambar dengan menggunakan filter median. Kelima, pemilahan sub-gambar dengan menggunakan filter deteksi tepi Canny. Keenam, temukan titik tengah dari setiap sub-gambar. Ketujuh, pemulihan dengan menggunakan pemasangan kurva polinomial ke-5. Kedelapan, tentukan sudut Cobb dengan menggunakan prinsip gradien persamaan garis lurus. Gambar 1 menunjukkan alur langkah-langkah dalam penelitian. Sebagai pertimbangan, kami membandingkan perhitungan sudut Cobb secara manual dengan perhitungan otomatis. Perhitungan manual akan dilakukan oleh dokter, sementara perhitungan otomatis akan dilakukan oleh sistem.

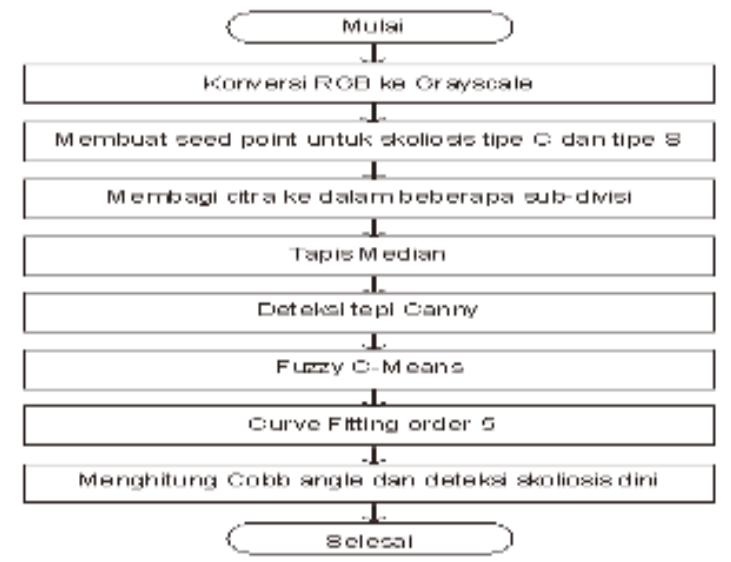

Gambar 1. Alur Penelitian

Agar komputasi lebih ringan, citra digital X-ray akan diproses dalam bentuk grayscale. Sehingga, semua citra RGB akan dikonversikan kedalam grayscale. Untuk menghasilkan kurva polinomial, dibutuhkan penempatan titik-titik sepanjang tulang belakang. Titik-titik tersebut didapatkan dengan menggunakan seed point sebagai pemicu untuk titik lainnya yang nantinya akan dihasilkan secara otomatis. Karena terdapat dua jenis skoliosis, analisis dari pemrosesan sudut Cobb akan dibagi menjadi dua prosedur. Untuk tipe $\mathrm{C}$ dikembangkan dengan menggunakan tiga seed point, dan empat seed point untuk tipe S. Untuk tipe C, seed point diletakkan pada bagian atas, hanya pada local maxima atau hanya local minima saja, serta ruas bagian bawah tulang belakang, sementara 
untuk tipe $\mathrm{S}$, seed point diletakkan pada bagian atas, local maxima, local minima dan ruas bagian bawah tulang belakang, seperti yang terdapat pada Gambar 2.

Tentu saja, sebelum memulai pengukuran, pertama-tama kita harus menentukan tipe skoliosisnya. Untuk menentukan seed point, cobalah untuk mencocokkan pada titik tengah ruas tulang belakang untuk hasil yang lebih baik, metode ini juga digunakan dalam beberapa penelitian [3] [6] [7]. Pada langkah berikutnya, seed point akan membagi citra menjadi beberapa bagian/subdivision.

Untuk mengetahui titik-titik lokasi dari tulang belakang, pertama-tama seorang dokter harus menetapkan ROI dari citra tersebut. Terdapat 3 titik ROI untuk tipe C dan 4 titik untuk tipe S, seperti yang terlihat pada Gambar 2. Kemudian citra tersebut akan dibagi kedalam 8 bagian atau sub-bagian untuk tipe $C$ dan 12 bagian untuk tipe S. Setiap sub-bagian akan menghasilkan titik-titik secara otomatis. Pembagian citra akan membuat perhitungan terfokus pada ROI. ROI dapat dihitung dengan menggunakan Persamaan. 1, Persamaan. 2, dan Persamaan 3 seperti yang terlihat pada Gambar 3 dan Gambar 4. Tipe $\mathrm{C}$ memiliki dua delta, yaitu $\Delta \mathrm{A}$ dan $\Delta \mathrm{B}$, sementara tipe $\mathrm{S}$ memiliki 3 delta $\Delta \mathrm{A}, \Delta \mathrm{B}$, dan $\Delta \mathrm{C}$

$$
\begin{aligned}
\Delta A & =\frac{\left|X_{1}-X_{2}\right|}{4} \\
\Delta B & =\frac{\left|X_{2}-X_{3}\right|}{4} \\
\Delta C & =\frac{\left|X_{3}-X_{4}\right|}{4}
\end{aligned}
$$
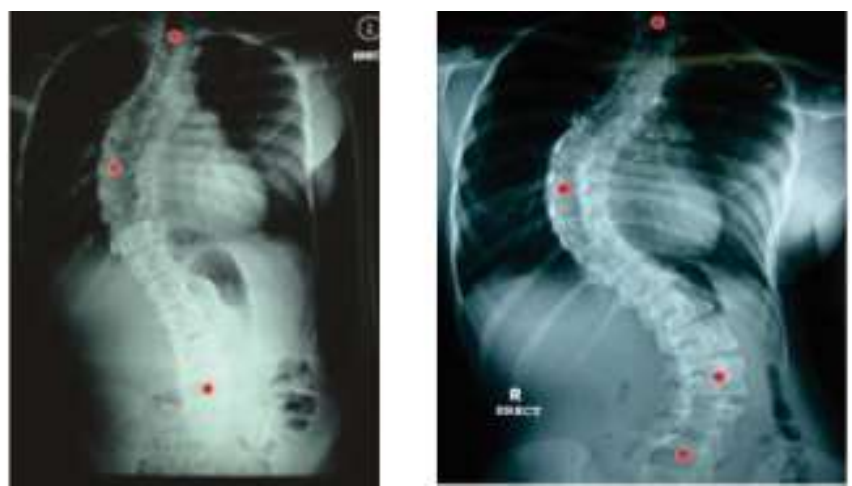

Gambar 2. Seed point pada tipe C (kiri) dan tipe S (kanan)

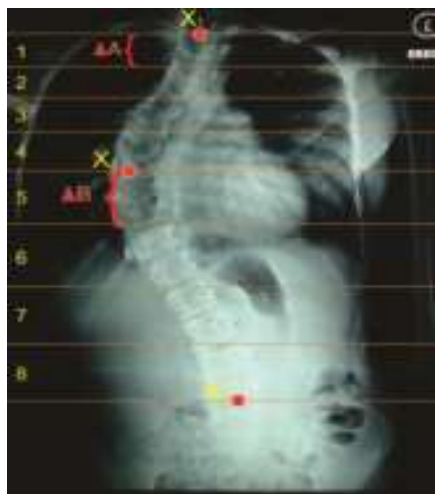

Gambar 3. Sub-divisi untuk citra Tipe C

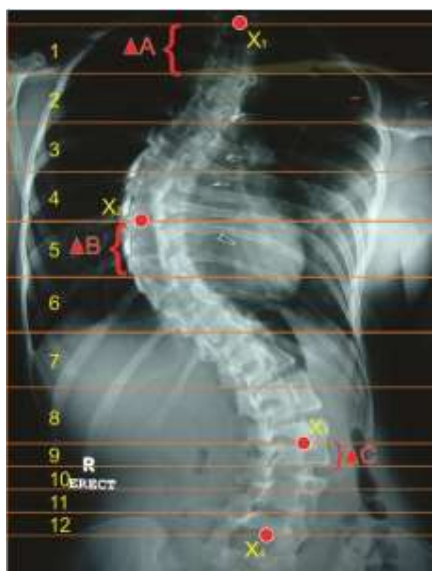

Gambar 4. Sub-divisi untuk citra Tipe $\mathrm{S}$ 
$J_{m}=\sum_{i=1}^{N} \sum_{j=1}^{C} u_{i j}^{m}\left\|x_{i}-c_{j}\right\|^{2}, 1 \leq m<\infty$

$\frac{y-y_{1}}{y_{2}-y_{1}}=\frac{x-x_{1}}{x_{2}-x_{1}}$

$\theta=\tan ^{-1}\left|\frac{y_{2}-y_{1}}{x_{2}-x_{1}}\right|$

\subsection{Penentuan ROI}

Setelah sub-divisi citra telah definisikan, perhitungan dimulai dari bagian 1 hingga bagian 8 untuk tipe $\mathrm{C}$ dan bagian 1 hingga bagian 12 untuk tipe S. Kemudian setiap sub-divisi ditapis menggunakan tapis median yang bertujuan agar X-ray tidak buram, dan informasi ROI akan semakin jelas terlihat saat dilakukan operasi deteksi tepi, seperti terlihat pada Gambar 5. Citra yang sudah melalui proses tapis median kemudian melewati proses deteksi tepi Canny [17] untuk menyimpulkan tekstur tulang belakangnya, seperti yang terlihat pada Gambar 6. Canny merupakan sebuah algoritme deteksi tepi yang memiliki 4 langkah sebagai berikut [18].

1. Image smoothing dengan menggunakan tapis Gaussian

2. Tentukan besaran dan orientasi gradien

3. Terapkan supresi non-maxima terhadap besaran gradien.

4. Menghubungkan dan memberikan batasan dengan menetapkan batasan rendah dan tingginya.

Hasil dari deteksi tepi akan berupa citra biner, sehingga titik pusat setiap sub-divisi citra tersebut dapat ditemukan. Penemu metode Fuzzy C-Means (FCM) untuk penentuan titik pusat pertama kali diusulkan oleh Dr. Bezdek [19]. FCM sering digunakan pada pengenalan pola suatu objek pada bidang ilmu pattern recognition dan berbagai keilmuan lainnya. FCM ini berbasis pada minimalisasi dari fungsi objek seperti tertera pada Persamaan 4. Dimana $m$ adalah bilangan riil lebih besar dari $1, u_{i j}$ adalah derajat keanggotaan dari $x_{i}$ dalam kluster $j, x_{i}$ adalah adalah $i^{\text {th }}$ dari dimensi ke $d$ data yang diukur, $c_{j}$ adalah dimensi ke $d$ dari pusat kluster, dan $\|*\|$ adalah norm dari kesamaan antara data yang diukur dengan pusat kluster.

Pada penelitian kami, metode FCM tersebut digunakan pada setiap citra untuk menetapkan 11 titik pusat untuk skoliosis tipe $\mathrm{C}$ dan 16 titik untuk skoliosis tipe $\mathrm{S}$ dengan nilai parameter $\mathrm{k}=3$. Semua titik yang ditetapkan baik secara manual maupun otomatis dapat dikelompokkan seperti yang terlihat pada Gambar 7 dan Gambar 8 . Titik merah ditetapkan secara manual oleh dokter, dan titik kuning merupakan hasil dari pengelompokan FCM pada setiap sub-divisi. Titik-titik tersebut merupakan estimasi titik pusat ruas tulang belakang yang kemudian akan diproses dengan menggunakan pencocokan kurva polinomial.

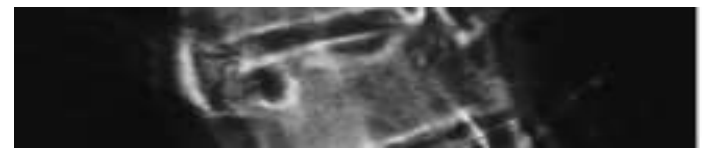

Gambar 5. Median filtering pada sub-divisi gambar

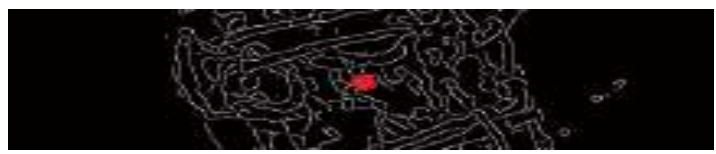

Gambar 6. Estimasi titik pusat pada sub-gambar

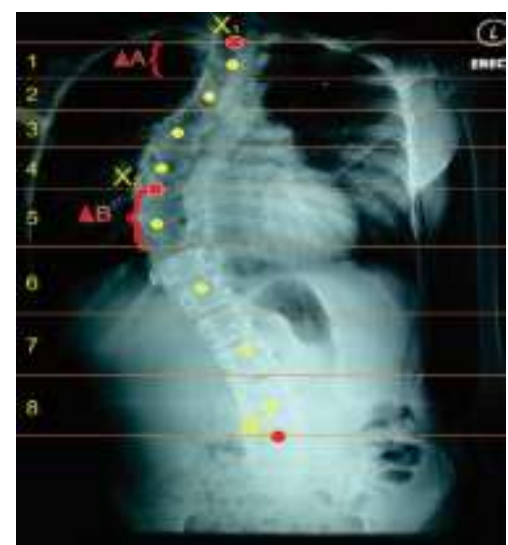

Gambar 7. Keseluruhan estimasi titik pusat pada tipe C 


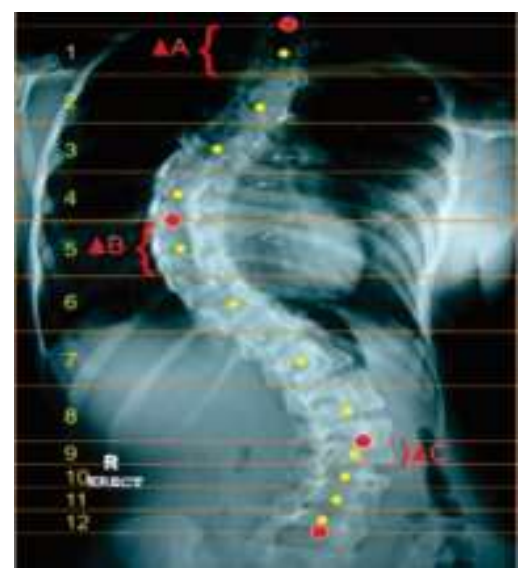

Gambar 8. Keseluruhan estimasi titik pusat pada tipe $S$

\subsection{Perhitungan sudut Cobb}

Dari total titik-titik estimasi, kemudian lereng kurva skoliosis dapat dilakukan pendekatan menggunakan fungsi curve fitting polinomial order ke-5 seperti yang terlihat pada Gambar 9. Dari kurva yang telah terbentuk, maka gradien kurva tersebut dapat dihitung menggunakan tangen sepanjang kurva polinomial. Menggunakan persamaan gradien yang melalui dua buah titik, dengan jarak titik permulaan $\left(x_{2}, y_{2}\right)$ dan titik akhir $\left(x_{1}, y_{1}\right)$ dengan jarak 50 pixel, seperti yang terlihat dalam Persamaan 5. Pada kondisi skoliosis tipe C, terdapat dua endplate, yaitu, endplate bagian atas dan endplate bagian bawah. Sementara itu, pada skoliosis tipe $\mathrm{S}$, terdapat tiga endplate, bagian atas, tengah dan bawah, yang mana keduanya dapat dilihat pada Gambar 9a dan 9b. Maka dari itu, persamaan sistem linier dapat dirumuskan seperti pada Persamaan 5. Sehingga sudut tegak lurus kurva yang berpotongan dapat dihitung menggunakan Persamaan 6. Persamaan 6 tersebut dikenal dengan istilah sudut Cobb.
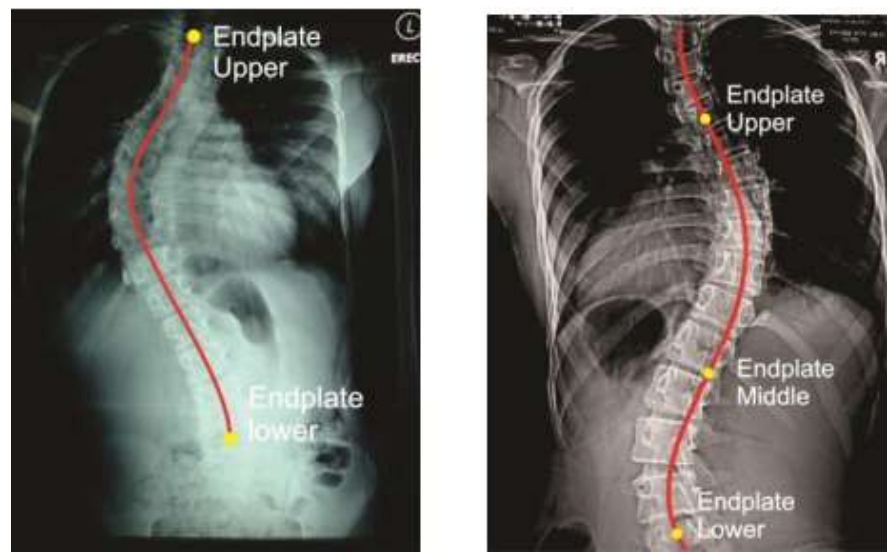

Fig. 9. Perkiraan sudut Cobb, (a) Tipe C, (b) Tipe S

\section{ANALISA DAN PEMBAHASAN}

Berdasarkan penjelasan sebelumnya, kami telah menguji sistem dengan menggunakan data berupa 28 citra pasien penyandang skoliosis. Dari 10 data merupakan kurva skoliosis tipe C dan 18 data skoliosis tipe S, hasil yang didapatkan tertera pada Tabel 1, Tabel 2 dan Tabel 3. Kami membandingkan hasil dari perkiraan sudut Cobb secara otomatis dengan manual yang dilakukan oleh dokter.

Merujuk pada Tabel 1, menunjukkan bahwa tingkat penyimpangan maksimal kurva adalah sebesar $3.0^{\circ}$ yaitu pada data 7 . Penyimpangan minimum $0.9^{\circ}$ pada data 3 dari data kurva tunggal (tipe $\mathrm{C}$ ), dan penyimpangan rata-rata sebesar $1.81^{\circ}$. Berdasarkan Tabel 2 sebagai hasil dari kurva thoracal (tipe $S$ ), penyimpangan rata-rata sebesar $1.83^{\circ}$, dan penyimpangan maksimum sebesar $4.16^{\circ}$ pada data 12 , dan penyimpangan minimium $0.67^{\circ}$ pada data 16. Berdasarkan Tabel 3 untuk hasil dari kurva lumbal tulang belakang (tipe $S$ ), rata-rata penyimpangan sebesar $2.45^{\circ}$, dengan penyimpangan maksimum $4.50^{\circ}$ pada data 13 dan penyimpangan minimum sebesar $0.98^{\circ}$ pada data 10. Berdasarkan hasil tersebut dapat dianalisis bahwa beberapa citra memiliki kualitas rendah, sehingga posisi titik pusat menjadi kurang jelas. Citra X-ray yang memiliki kualitas baik akan meningkatkan akurasi dari sistem.

Tabel 1. Perbandingan Cobb manual dengan otomatis untuk Tipe $\mathrm{C}$

\begin{tabular}{cccc}
\hline Data & Manual $\left({ }^{\circ}\right)$ & Otomatis $\left({ }^{\circ}\right)$ & Penyimpangan $\left({ }^{\circ}\right)$ \\
\hline 1 & 59.92 & 62.68 & 2.76 \\
2 & 64.85 & 63.58 & 1.27 \\
\hline
\end{tabular}


Hal: 9 - 16 | DOI: 10.30865/mib.v3i1.992

$\begin{array}{cccc}3 & 41.98 & 41.08 & 0.9 \\ 4 & 66.17 & 67.20 & 1.03 \\ 5 & 40.91 & 42.24 & 1.33 \\ 6 & 42.87 & 44.23 & 1.36 \\ 7 & 73.80 & 70.80 & 3.00 \\ 8 & 45.82 & 43.45 & 2.37 \\ 9 & 47.36 & 45.67 & 1.69 \\ 10 & 38.62 & 40.98 & 2.36 \\ & & 1.81\end{array}$

Dalam beberapa kondisi, titik pusat tidak harus berada ditengah-tengah ruas tulang belakang. Akan tetapi, dapat sedikit kekiri atau kekanan dari pusat massa, dan selama masih di dalam area yang diamati. Kesalahan biasanya disebabkan oleh kualias gambar yang buruk, sehingga memengaruhi hasil proses deteksi tepi. Titik pusat dihasilkan secara otomatis dengan mengacu pada titik pusat sebelumnya, sehingga akan mencegah tmbulnya kekeliruan saat menciptakan titik pusat berikutnya.

Berdasarkan tipe kurva, terdapat dua prosedur pengukuran untuk tipe $\mathrm{S}$ dan tipe $\mathrm{C}$. Pertama, prosedur perhitungan skoliosis tipe thoracic dengan kemiringan arah kanan. Kedua, prosedur pengukuran untuk skoliosis thoracic sisi kiri dan kemiringan pinggang arah kanan. Tipe $\mathrm{C}$ dapat dikategorikan kedalam dua prosedur, yang ditentukan dari arah kemiringannya ke arah sisi kiri atau sisi kanan. Hal ini dilakukan sebagai informasi tambahan pada bentuk skoliosis.

Data X-ray yang digunakan dalam penelitian ini merupakan milik pasien penyandang skoliosis pribadi dan juga dari anggota organisasi MSI di Jawa Tengah, Indonesia. Terdiri dari 28 sampel data dengan jenis kurva yang berbeda-beda, 10 data merupakan skoliosis tipe $\mathrm{C}$ dan 18 data skoliosis tipe S. Dimana data tersebut diambil dengan menggunakan kamera digital. Resolusi puncak sebesar 20 MegaPixel yang diperbaiki dengan menggunakan pengubah ukuran gambar adaptif, agar ketika proses filtrasi selesai dilakukan, tidak akan menghasilkan citra baru yang perbedaannya terlalu signifikan.

Tabel 2. Perbandingan Cobb manual vs otomatis untuk thoracal Tipe $S$

\begin{tabular}{cccc}
\hline Data & Manual Atasi $\left({ }^{\circ}\right)$ & Otomatis Atas $\left({ }^{\circ}\right)$ & $\begin{array}{c}\text { Penyimpangan } \\
\text { Atas }\left({ }^{\circ}\right)\end{array}$ \\
\hline 1 & 24.94 & 23.06 & 1.88 \\
2 & 53.71 & 56.23 & 2.52 \\
3 & 87.45 & 86.50 & 0.95 \\
4 & 57.27 & 55.58 & 1.69 \\
5 & 84.81 & 85.34 & 0.53 \\
6 & 42.11 & 45.89 & 3.78 \\
7 & 68.32 & 70.87 & 2.55 \\
8 & 87.35 & 85.84 & 1.51 \\
9 & 86.23 & 84.01 & 2.22 \\
10 & 42.92 & 41.74 & 1.18 \\
11 & 80.48 & 79.63 & 0.85 \\
12 & 33.50 & 37.66 & 4.16 \\
13 & 62.53 & 63.14 & 0.61 \\
14 & 36.60 & 38.63 & 2.03 \\
15 & 35.96 & 37.90 & 1.94 \\
16 & 53.00 & 53.67 & 0.67 \\
17 & 66.99 & 65.35 & 1.64 \\
18 & 40.35 & 42.72 & 2.37 \\
& Rata-rata penyimpangan & 1.83 \\
\hline
\end{tabular}

Tabel 3. Perbandingan Cobb manual dengan otomatis untuk kurva lumbal (Tipe S)

\begin{tabular}{cccc}
\hline Data & Manual Bawah $\left({ }^{\circ}\right)$ & Otomatis Bawah $\left({ }^{\circ}\right)$ & $\begin{array}{c}\text { Penyimpangan } \\
\text { Bawah }\left({ }^{\circ}\right)\end{array}$ \\
\hline 1 & 20.09 & 17.38 & 2.71 \\
2 & 36.16 & 38.44 & 2.28 \\
3 & 65.36 & 67.64 & 2.28 \\
4 & 38.06 & 36.34 & 1.72 \\
5 & 77.69 & 80.33 & 2.64 \\
6 & 35.49 & 36.63 & 1.14 \\
7 & 66.80 & 69.90 & 3.10 \\
8 & 66.99 & 68.88 & 1.89 \\
9 & 72.60 & 70.66 & 1.94 \\
\hline
\end{tabular}




$\begin{array}{llcc}\mathbf{1 0} & 64.91 & 65.89 & 0.98 \\ 11 & 63.88 & 65.76 & 1.88 \\ 12 & 35.04 & 38.52 & 3.48 \\ \mathbf{1 3} & 88.62 & 84.12 & 4.50 \\ 14 & 29.00 & 31.53 & 2.53 \\ 15 & 28.19 & 30.28 & 2.09 \\ 16 & 40.00 & 43.62 & 3.62 \\ 17 & 46.15 & 48.78 & 2.63 \\ 18 & 33.71 & 36.46 & 2.75 \\ & & \text { Rata-rata penyimpangan } & 2.45\end{array}$

FCM memiliki keuntungan yang signifikan dibanding metode lain yang juga digunakan untuk menentukan kurva skoliosis, karena komputasi yang ringan dan beban perhitungan cepatnya dan dapat beradaptasi dengan derau di sekeliling tulang belakang. Waktu yang dibutuhkan untuk menjalankan semua proses dalam metode yang kami usulkan adalah sekitar 10 detik. Hal ini dilakukan dengan menggunakan spesifikasi computer i5 (3.0 GHz) dan 12 GB RAM. Waktu yang dibutuhkan oleh praktisi atau dokter untuk menentukan seed point kurang dari 5 detik dan perhitungan komputer untuk mengukur sudut Cobb menghabiskan waktu sekitar 5 detik. Sebagai perbandingan dengan menggunakan spesifikasi komputer yang sama, metode yang kami usulkan lebih cepat dari metode template matching Sum of Squared Different (SSD) [16] yang memerlukan waktu sekiar 40 detik. Template matching memerlukan banyak sekali memori untuk mengecek kemiripan citra dari sampel yang disediakan, sementara metode yang kami usulkan mencoba mengekstrak ciri tersebut menggunakan deteksi tepi dan pencarian titik pusat dilakukan menggunakan metode curve fitting. Cara ini merupakan percobaan dari sudut pandang yang lain namun dengan tujuan yang sama yaitu mencari bentuk dari kurva skoliosis.

Berdasarkan hasil percobaan, rata-rata penyimpangan terbaik dengan menggunakan sistem ini adalah sekitar $2.45^{\circ}$ yang artinya sistem ini masih dalam batas toleransi karena belum menyentuh angka $6^{\circ}$. Dengan demikian, dengan menggunakan sistem ini, dokter dan pasien dapat menghemat waktu konsultasi. Tahap terakhir adalah deteksi dini skoliosis berdasarkan kurva yang telah dihasilkan sistem. Merujuk jurnal penelitian ini [4], klasifikasi skoliosis dapat ditentukan dengan mengikuti aturan berikut seperti yang tertera pada Tabel 4.

Tabel 4. Klasifikasi Skoliosis

\begin{tabular}{c|c}
\hline Sudut kemiringan $\operatorname{Cobb}\left(^{\circ}\right)$ & Klasifikasi \\
\hline$<10^{\circ}$ & Normal \\
\hline $10^{\circ}<x<25^{\circ}$ & Ringan \\
\hline $25^{\circ}<\mathrm{x}<45^{\circ}$ & Sedang \\
\hline$>45^{\circ}$ & Parah \\
\hline
\end{tabular}

Untuk penelitian berikutnya, akan difokuskan untuk memperoleh citra masukan dari satu alat saja, khususnya hasil yang diperoleh dari mesin X-ray yang mampu menghasilkan citra dalam format digital dengan perhitungan menggunakan smartphone android.

\section{KESIMPULAN}

Algoritme yang digunakan sistem ini memerlukan biaya yang rendah dan mudah digunakan oleh semua orang, tak hanya dokter saja, pasien juga dapat menggunakannya. Algoritme yang kami kembangkan juga kompatibel dengan semua jenis komputer dan smartphone, karena sistem komputasinya yang ringan. Jadi, dengan menggunakan sistem ini, dokter dan pasien dapat menghemat waktu. Sistem ini masih dapat dikembangkan lagi agar menjadi lebih baik dan lebih sederhana sehingga memungkinkan untuk pengembangan pada perangkat seluler atau dengan menggunakan platform yang lain. Sistem yang kami kembangkan memiliki hasil yang baik yaitu sebesar $2.45^{\circ}$, nilai ini masih di bawah nilai intraobserver, yang artinya sistem ini masih dalam batas toleransi.

\section{REFERENCES}

[1] L. Ramirez, S. Member, N. G. Durdle, V. J. Raso, and D. L. Hill, "A Support Vector Machines Classifier to Assess the Severity of Idiopathic Scoliosis From Surface Topography,” IEEE Trans. Inf. Technol. Biomed., vol. 10, no. 1, pp. 84-91, 2006.

[2] T. A. Sardjono, M. H. Wilkinson, A. G. Veldhuizen, P. M. van Ooijen, K. E. Purnama, and G. J. Verkerke, "Automatic Cobb Angle Determination from Radiographic Images," Spine (Phila. Pa. 1976)., vol. 38, no. 20, p. 1, 2013.

[3] H. A. R. De Santiago et al., "The influence of vision and support base on balance during quiet standing in patients with adolescent idiopathic scoliosis before and after posterior spinal fusion," Spine J., vol. 13, no. 2013, pp. 1470-1476, 2017.

[4] J. Chowanska, T. Kotwicki, K. Rosadzinski, and Z. Sliwinski, "School screening for scoliosis : can surface topography replace examination with scoliometer ?," Scoliosis Spinal Disord., vol. 7, no. 9, pp. 1-7, 2012.

[5] H. Takanashi et al., "Development of Next Generation Apparatus for Measurement of Curve Degree in Idiopathic Scoliosis," in International Conference on Advanced Mechatronic Systems, 2012, pp. 597-602.

[6] D. Mauroy, J. C. De Mauroy, C. Lecante, F. Barral, and S. Pourret, "Prospective study and new concepts based on scoliosis detorsion of the first 225 early in-brace radiological results with the new Lyon brace: ARTbrace Prospective study and new concepts based on scoliosis detorsion of the first 225 early in-brace radiolo," Scoliosis Spinal Disord., vol. 9, pp. 1-18, 2014. 
[7] J. Mo and M. Jezer, "Determination of the human spine curve based on laser triangulation," BMC Med. Imaging, vol. 15, pp. 1-11, 2015.

[8] B. Samuvel, V. Thomas, M. M.G., and R. K. J., "A Mask Based Segmentation Algorithm for Automatic Measurement of Cobb Angle from Scoliosis X-Ray Image,” 2012 Int. Conf. Adv. Comput. Commun., pp. 110-113, Aug. 2012.

[9] J. Zhang, E. Lou, L. H. Le, D. L. Hill, J. V Raso, and Y. Wang, "Automatic Cobb measurement of scoliosis based on fuzzy Hough Transform with vertebral shape prior.," J. Digit. Imaging, vol. 22, no. 5, pp. 463-72, Oct. 2009.

[10] R. Morissy, G. Goldsmith, E. Hall, D. Kehi, and G. Cowie, "Measurement of the Cobb angle on radiographs of patients who have scoliosis. Evaluation of intrinsic error.," Bone Jt. Surg AM, vol. 72, pp. 320-327, 1990.

[11] M. Benjelloun, H. Tellez, S. Mahmoudi, M. Benjelloun, and H. Tellez, "Template Matching Method for Vertebra Region Selection," in Information and Communication Technologies, 2006, pp. 1119-1124.

[12] M. Benjelloun, H. Tellez, and S. Mahmoudi, "Vertebra Edge Detection Using Polar Signature," 18th Int. Conf. Pattern Recognit., vol. 1, pp. $476-479,2006$

[13] L. Duong, F. Cheriet, and H. Labelle, "Automatic detection of scoliotic curves in posteroanterior radiographs.," IEEE Trans. Biomed. Eng., vol. 57, no. 5, pp. 1143-51, May 2010.

[14] A. Jose, D. M. D. K, and N. Joseph, "Performance Study of Edge Detection Operators," no. Ices, pp. 7-11, 2014.

[15] a Rajasekaran and Senthilkumar, "Image Denoising Using Median Filter with Edge Detection Using Canny Operator," vol. 3, no. 2, pp. $1-5,2014$.

[16] B. A. Kusuma, H. A. Nugroho, and S. Wibirama, "Spinal curvature determination from scoliosis X-Ray image using sum of squared difference template matching," Proc. - 2016 2nd Int. Conf. Sci. Technol. ICST 2016, pp. 29-34, 2017.

[17] J. Canny, “A computational approach to edge detection.," IEEE Trans. Pattern Anal. Mach. Intell., vol. 8, no. 6, pp. 679-698, 1986.

[18] I. Nurhaida, R. Manurung, and A. M. Arymurthy, "Performance Comparison Analysis Features Extraction Methods for Batik Recognition," Icacsis 2012, pp. 207-212, 2012.

[19] Bezdek, J. C., Ehrlich R., Full W., "FCM, The Fuzzy C-Means Clustering Algorithm," Journal Computer and Geosciences, vol. 10, no. 2-3, pp. 191-203, 1984 